\title{
Extra- and intracerebral course of the recurrent artery of Heubner
}

\author{
P. Maga ${ }^{1 *}$, K.A. Tomaszewski2 ${ }^{*}$, A. Pasternak2 ${ }^{2}$, J. Zawiliński², R. Tomaszewska ${ }^{3}$, \\ I. Gregorczyk-Maga4, J. Skrzat ${ }^{2}$ \\ ${ }^{1}$ Department of Angiology, Jagiellonian University Medical College, Cracow, Poland \\ ${ }^{2}$ Department of Anatomy, Jagiellonian University Medical College, Cracow, Poland \\ ${ }^{3}$ Department of Pathology, Jagiellonian University Medical College, Cracow, Poland \\ ${ }^{4}$ Department of Paediatric Dentistry, Institute of Dentistry, Jagiellonian University Medical College, Cracow, Poland
}

[Received 8 January 2013; Accepted 7 February 2013]

Background: The aim of the current study was to analyse the extra- and intracerebral course of the recurrent artery of Heubner $(R A H)$ to provide detailed information for neurosurgeons operating in this area.

Materials and methods: The material for this study was obtained from cadavers (ages 31-75 years) during routine autopsies. A total of 70 human brains (39 male and 31 female) were examined. The material was collected not later than $48 \mathrm{~h}$ post-mortem. People who died due to neurological disorders were not included into the study. Right after dissection the arteries were perfused with either acrylic paint emulsion, polyvinyl chloride or Mercox CL-2R resin, through the Circle of Willis or electively through the $R A H$. The obtained material was analysed using a stereoscopic light microscope, magnification 2-40 $\times$.

Results: The RAH was present in 138 hemispheres with a mean of $1.99 \mathrm{RAH}$ per hemisphere (275 RAH in total). The mean RAH length was $25.2 \mathrm{~mm}$ and the mean $R A H$ diameter, in its place of origin, was $1 \mathrm{~mm}$. In 168 (61\%) cases the $R A H$ ran superiorly, in 88 (32\%) cases anteriorly, in 11 (4\%) cases inferiorly and in 8 (3\%) cases posteriorly to the $A 1$ segment. In $70.2 \%$ of the cases the course of the RAH was parallel to the anterior communicating artery $A 1$ segment, and in $29.8 \%$ of the cases the $R A H$ arched towards the olfactory tract. As the extracerebral course of the RAH was always tortuous, its length was 1 to 5 times the distance between its place of origin and the most lateral point of anterior perforated substance (APS) penetration. The intracerebral course of the RAH was almost always univectorial - towards the head of the caudate nucleus. The course of RAH branches depended on their number. When the number of RAHS and their branches was low, they separated immediately after penetrating the APS and formed multiple small branches. When the number of RAHs and branches was high, post-APS branching was less frequent and occurred in distal segments.

Conclusions: The origin and course of the RAH is highly variable. The $R A H$, in its extra- and intracerebral course, may join with the middle group of the lenticulostriate arteries or directly with the middle cerebral artery. This artery should be routinely identified during anterior communicating artery aneurysm clipping to prevent postoperative neurological deficits. (Folia Morphol 2013; 72, 2: 94-99)

Key words: recurrent artery of Heubner, distal medial striate artery, anterior communicating artery, anterior cerebral artery, course

Address for correspondence: K.A. Tomaszewski, MD, Department of Anatomy, Jagiellonian University Medical College, ul. Kopernika 12, 31-034 Kraków, Poland, tel/fax: +48 12 422-95-11, e-mail: krtomaszewski@gmail.com

*These authors contributed equally to this work. 


\section{INTRODUCTION}

The term "Heubner's artery" was first used in 1909 by Aitken, after Heubner's classical description of the vessel in 1872 [4]. Other authors called this vessel the long centralis artery [15], telencephalic artery [2], distal medial striate artery [6] or the rostral striate artery [1].

The recurrent artery of Heubner (RAH) arises at the level of the anterior communicating artery, most commonly from the $A 1$ or $A 2$ segment of the anterior cerebral artery (ACA), or at the junction of the ACA and the anterior communicating artery (ACOA) [8]. The first part of the artery is in the immediate vicinity of the ACA trunk, and then it runs posterolaterally, extending over the level of the internal carotid artery bifurcation and straight gyrus [16]. The RAH most frequently penetrates into the brain parenchyma at the level of the lateral part of the anterior perforated substance (APS) or the medial portion of the sylvian fissure [16]. It gives off numerous branches including those that supply the olfactory tract and triangle, the paraterminal gyrus, straight gyrus, subcallosal area and the orbitofrontal cortex [16]. The branches of the RAH also supply the anterior part of the caudate nucleus, the anterior third of the putamen, the apical part of the lateral segment of the globus pallidus and the anterior limb of the internal capsule [16].

Surgical interventions in the anterior part of the Circle of Willis can be complicated by obstruction or vascular damage to the RAH. This is usually caused by irregular clip placement, the fact of RAH being located in the immediate vicinity of the ACA trunk, or insufficient knowledge about its anatomical variations [16]. Classically, occlusion of the RAH results in hemiparesis with faciobrachial predominance, and is a well-recognised stroke syndrome in adults [2].

The aim of the current study was to analyse the extra- and intracerebral course of the RAH and provide detailed information for neurosurgeons operating in this area.

\section{MATERIALS AND METHODS}

The material for this study was obtained from cadavers (ages 31-75 years) during routine autopsies performed at the Department of Pathology, JagielIonian University Medical College (JUMC). A total of 70 human brains (39 male and 31 female), yielding a total of 140 hemispheres, were examined. The material was collected not later than $48 \mathrm{~h}$ post-mortem.
People who died due to neurological disorders were not included into the study.

The research protocol was approved by the JUMC Ethics Committee (registry KBET/270/B/2012).

After the removal from the cranium, the brains were stored in room temperature saline. Existing clots were removed using saline irrigation. Right after dissection the arteries were perfused (stable pressure of $120 \mathrm{~mm} \mathrm{Hg}$ ) with acrylic paint emulsion (Liqutiex R, Binney and Smith) [13, 14, 20], through the Circle of Willis or electively through the RAH. In case when the ACA and the middle cerebral artery (MCA) were perfused simultaneously, different acrylic colours were used. The perfusion was continued until cortical vessels were fully filled. Next the specimens have been stored in a $10 \%$ solution of formaldehyde for 2 weeks. Fixed brains were sectioned (slice 1-4 $\mathrm{mm}$ thick) along the coronal plane and dehydrated in increasing concentrations of the ethyl alcohol. Finally, the slices were placed in pure methyl salicylate for 2-3 weeks to enable tissue transparency.

To obtain corrosion specimens, the vessels were perfused with either polyvinyl chloride or Mercox CL-2R resin (Vilene Comp. Ltd., Japan) (Fig. 1) [17-19]. The corrosion was performed in high concentrations of potassium chloride.

To obtain RAH (Fig. 1) radiological pictures, lead oxide was added to polyvinyl chloride [3].

The obtained material was analysed using a stereoscopic light microscope (Technival 2 Carl Zeiss Jena), magnification 2-40×. Digital photographs were taken and later analysed using Java ImageJ (version 1.46d) software [10].

Statistical analysis was conducted using computer software Statistica 10.0 PL by Statsoft Poland. Elements of descriptive statistics were used (mean, standard deviation, percentage distribution).

\section{RESULTS}

Overall, the RAH was present in 138 hemispheres and absent in 2 cases, with a mean of 1.99 RAH per hemisphere (275 RAH in total). The RAH was present as a single vessel in $41(29.7 \%)$ hemispheres, as a double vessel in $60(43.5 \%)$ hemispheres and as a triple vessel in $34(24.6 \%)$ hemispheres. The quadruple variant was the rarest and was present only in $3(2.2 \%)$ hemispheres.

The RAH originated form the A1 segment of ACA in $26.2 \%$ of cases, from the ACA $A 2$ segment in $33.8 \%$ and in $40 \%$ from the ACA-ACoA level. 


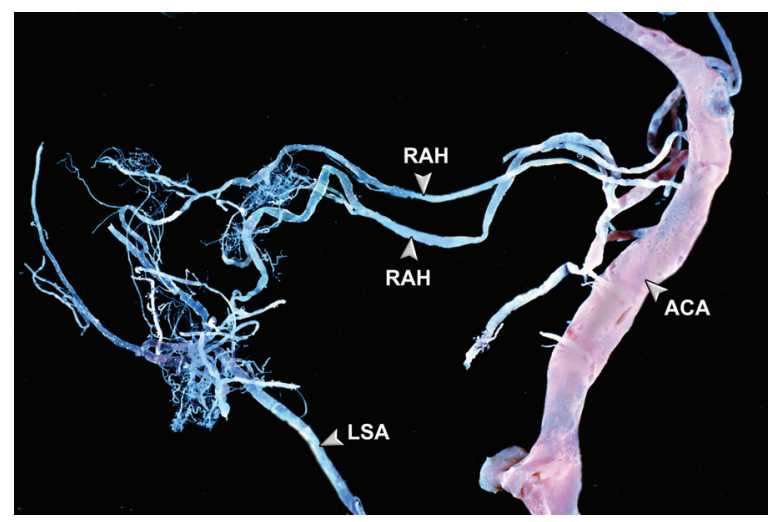

Figure 1. Radiological image of a corrosion-cast specimen injected with polyvinyl chloride and with added lead oxide; ACA — anterior cerebral artery; LSA — lenticulostriate arteries; RAH — recurrent artery of Heubner.

\section{RAH extracerebral course}

After branching of the ACA, the RAH took a recurrent course towards the A1 ACA and the M1 segment of the MCA, to reach the APS. The proximal RAH fragment accompanied the A1 ACA segment. In $168(61 \%)$ cases the RAH ran superiorly, in 88 (32\%) cases anteriorly, in 11 (4\%) cases inferiorly and in $8(3 \%)$ cases posteriorly to the A1 segment. It often happened that the same RAH ran superiorly, inferiorly, anteriorly and posteriorly to the A1 segment. Due to this, for statistical purposes, the relationship between the course of the RAH and the A1 ACA was defined by the RAH predominating position.

In $193(70.2 \%)$ cases the course of the RAH was parallel to the A1 ACA segment. In 82 (29.8\%) cases the RAH arched towards the olfactory tract. Nearing the APS, the RAH moved closer the MCA M1 segment. Before the entrance to the APS $179 \mathrm{RAH}$ (65.1\%) passed behind the MCA, always crossing over the M1 segment.

As the course of the RAH was always tortuous, its length was 1 to 5 times the distance between its place of origin and the most lateral point of APS penetration. The mean RAH length was 25.2 (range 10-45) $\mathrm{mm}$. The mean RAH diameter, in its place of origin, was 1 (range $0.2-2.5$ ) $\mathrm{mm}$. The multiplicity of $\mathrm{RAH}$ did not impact its length or diameter.

\section{RAH intracerebral course}

After passing the APS, the RAH together with the APS branches, always curved anteriorly and cranial (Fig. 2), never giving off branches backwards (Fig. 3).

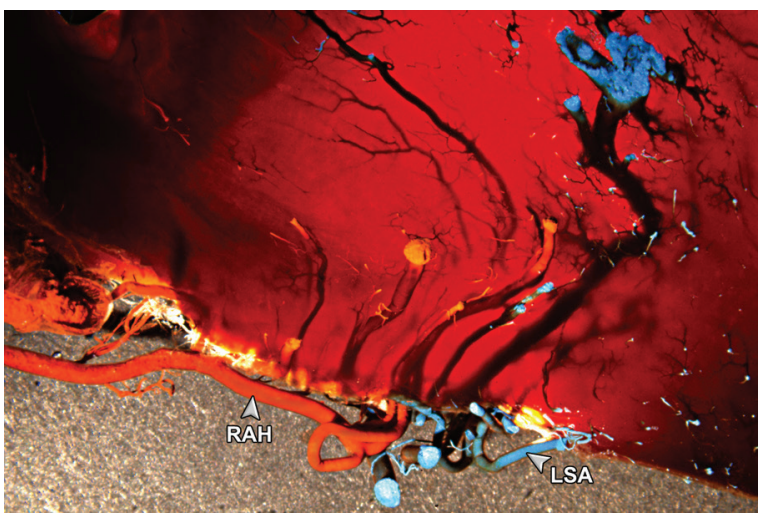

Figure 2. Brain - transverse section. Tissue transparency obtained using methyl salicylate. The RAH intracerebral course; LSA lenticulostriate arteries; RAH — recurrent artery of Heubner.

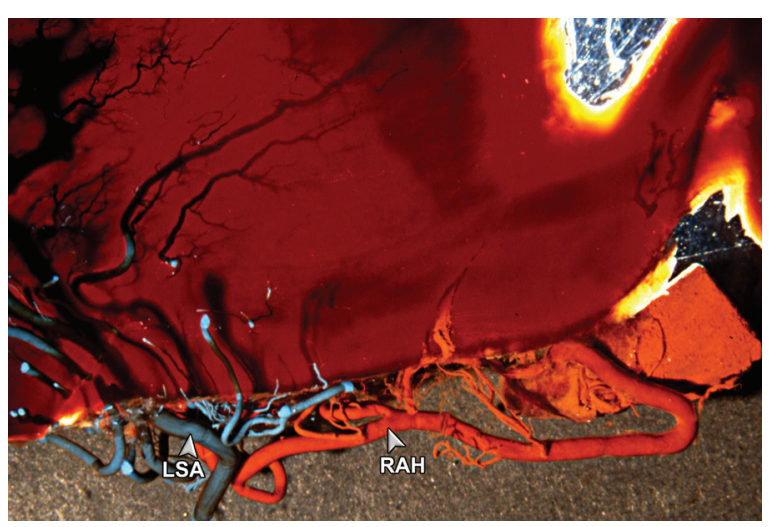

Figure 3. Brain - transverse section. Tissue transparency obtained using methyl salicylate. The border between RAH extra- and intracerebral course; LSA — lenticulostriate arteries; RAH — recurrent artery of Heubner.

The intracerebral course varied significantly across the samples, however, some tendencies were visible. The course of RAH was almost always univectorial towards the head of the caudate nucleus, meaning the RAH and APS branches were close to being parallel (Fig. 4). Often, in the head of the caudate nucleus, the branches supplying its lower part arched cranial and lateral, enlarging the RAH vascular supply. In these cases, the described branches were visible on the surface of the head of the caudate nucleus, from the side of the anterior horn of the lateral ventricle (Fig. 5).

The course of the branches depended on their number. When the number of RAHs and their branches was low, they separated immediately after penetrating the APS and formed multiple small branches (Fig. 6). When the number of RAHs and branches 


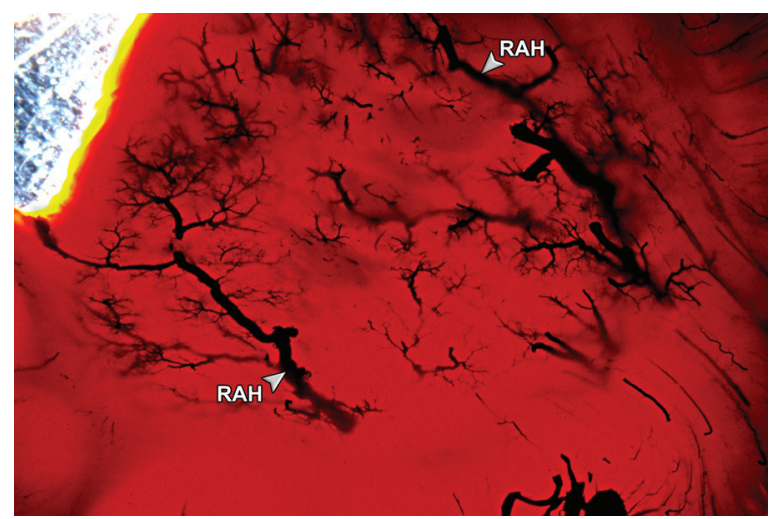

Figure 4. Brain - transverse section. Tissue transparency obtained using methyl salicylate. The recurrent artery of Heubner (RAH) and anterior perforated substance branches close to being parallel.

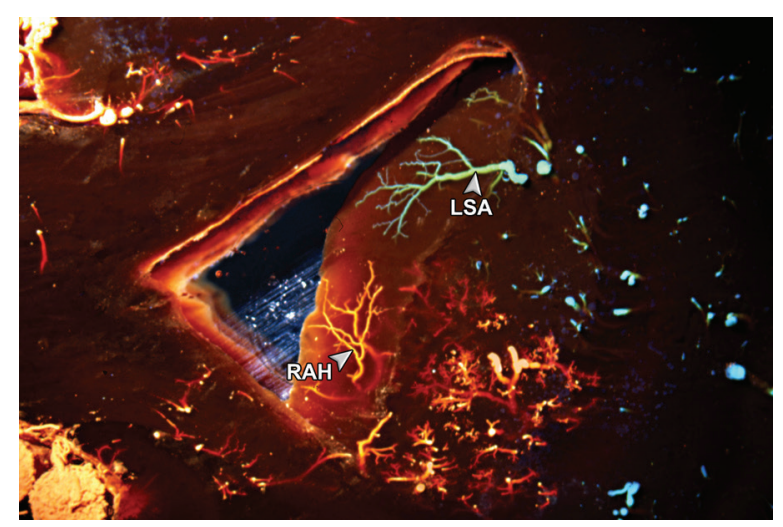

Figure 5. Brain - transverse section. Tissue transparency obtained using methyl salicylate. RAH branches visible on the surface of the head of the caudate nucleus, from the side of the anterior horn of the lateral ventricle. LSA — lenticulostriate arteries; RAH - recurrent artery of Heubner.

was high, post-APS branching was less frequent and occurred in distal segments (Fig. 4).

The RAH tortuous course could be observed in the majority of the specimens (Figs. 4, 6). As almost every branch passed through more than one brain structure it would be impossible to adequately name them (Fig. 7).

In 9 hemispheres (6.5\% of hemispheres with RAH present) there were intracerebral junctions between the APS branches originating from the RAH and the medial group of the lenticulostriate arteries (LSA), that branch off the MCA. The diameter of these anastomoses ranged from 0.1 to $0.2 \mathrm{~mm}$ (Fig. 1). Among the 9 hemispheres, twice it happened that the acrylic emulsion passed from the MCA through the LSA to the RAH on the base of the brain. In these specimens no anastomoses were present (Fig. 8).

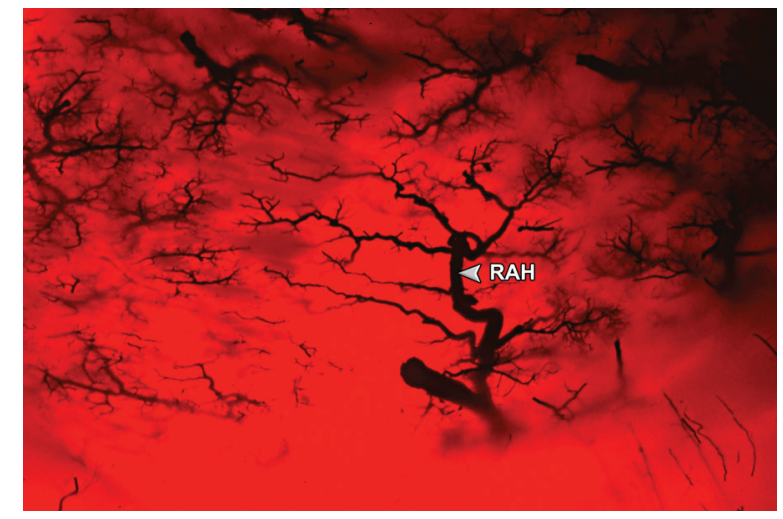

Figure 6. Brain — transverse section. Tissue transparency obtained using methyl salicylate. Course of the recurrent artery of Heubner (RAH) after penetrating the anterior perforated substance.

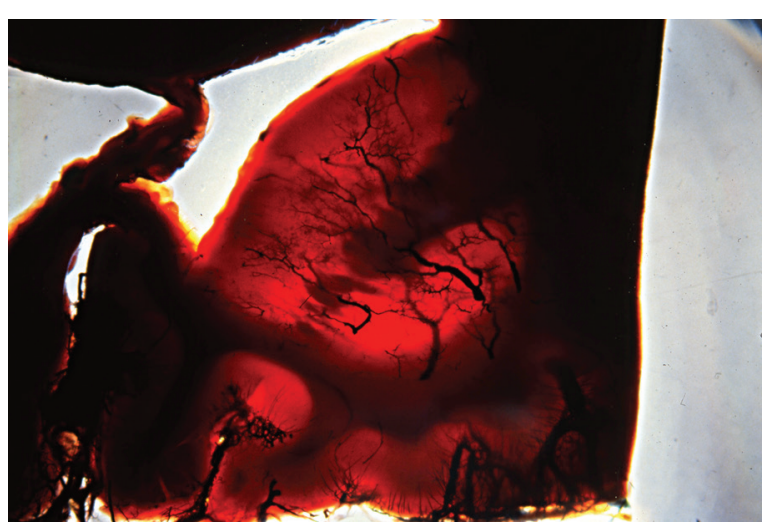

Figure 7. Brain - transverse section. Tissue transparency obtained using methyl salicylate. Multiplicity of recurrent artery of Heubner branches.

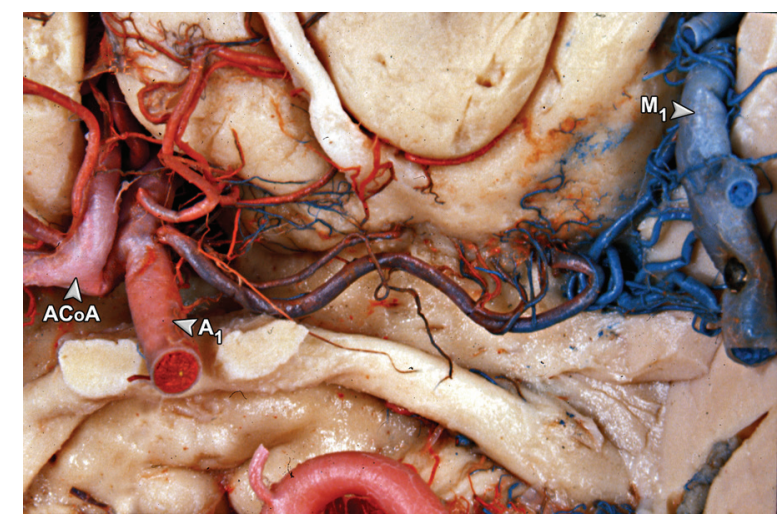

Figure 8. Brain — base. The vessels injected with acrylic paint emulsion. Acrylic paint emulsion can be seen passing from the middle cerebral artery, through the lenticulostriate arteries to the recurrent artery of Heubner, with no anastomoses present; $\mathrm{ACo}$ - anterior communicating artery. 


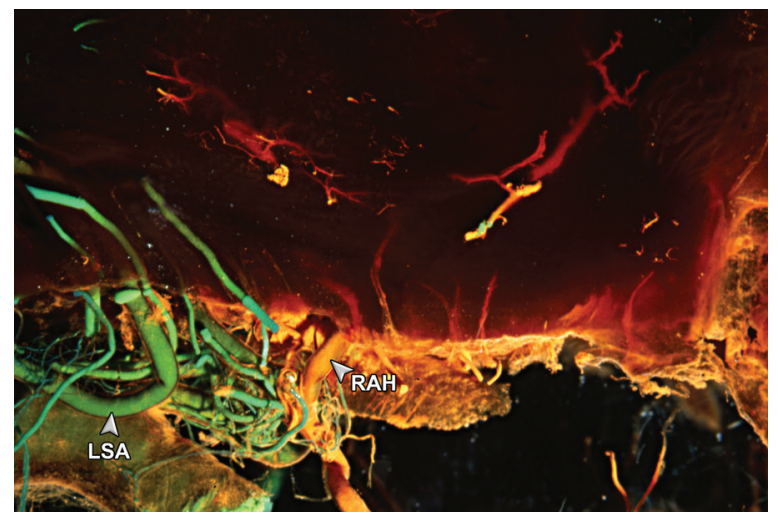

Figure 9. Brain — transverse section. Tissue transparency obtained using methyl salicylate. RAH anastomoses can be seen; LSA — lenticulostriate arteries; RAH — recurrent artery of Heubner.

In 6 hemispheres the anastomoses were located in the putamen and in 3 hemispheres in the medial globus pallidus (Fig. 9). Samples obtained using corrosion-casting presented vessel junctions of a diameter below $0.1 \mathrm{~mm}$ (Fig. 1).

\section{DISCUSSION}

The aim of this study was to analyse the extra- and intracerebral course of the RAH to provide detailed information for neurosurgeons operating in this area. To the best of the authors' knowledge, this is the first study to describe in detail the intracerebral course of the RAH.

About one quarter to one third of all treated cerebral aneurysms are found in the ACoA area [11]. Knowing the vascular anatomy and its variations is very important for the neurosurgeons operating in this area. Information about the course of the RAH is valuable to the surgeon who is considering vascular procedures that involve this vessel.

The RAH has been described as originating from the internal carotid, middle cerebral, or anterior choroidal arteries [2]. If one considers the classical description of the vessel as originating in the ACoA region [4], with a typical recurrent course and a constant point of penetration and areas of supply, it can safely be assumed that those cases would correspond to large perforating vessels off the proximal A1 segment, internal carotid, anterior choroidal or proximal middle cerebral arteries.

Perlmutter and Rothon [12] described that the recurrent artery of Heubner coursed anteriorly to the A1 segment in $60 \%$ of the cases and superiorly in $40 \%$. In a study by Gomes et al. [2], 3 types of recurrent courses were observed. In type I, or superior course, seen in $63 \%$ of the arteries, the artery followed the superior wall of the A1 segment. In type II, or anterior course, the arteries found in $34 \%$ of specimens maintained a rostral position in relation to the A1 segment. In type III, or posterior course, seen in 3\% of the arteries, these vessels took a posterior course in the APS. In this study the data was almost identical: $61 \%, 32 \%$ and $3 \%$, respectively. Other authors $[3,8]$ have also shown the predominance of the type I or type II course.

The RAH usually penetrates the brain parenchyma at the level of the APS or the medial part of the sylvian fissure. Most studies have confirmed that the RAH terminates by penetrating the brain parenchyma at the level of the medial or lateral APS in $>80 \%$ of cases $[2,9,12]$.

In type I and type II courses, the adventitia-arachnoid adherence with strands must be dissected carefully [7, 12]. Some authors attempt microvascular reconstructive procedures if the artery is involved in the wall of an aneurysmatic lesion, closed by an atherosclerotic occlusion or damaged in manipulations [2, 3]. The posterior course of the RAH is uncommon and the artery can be missed and easily injured during temporary clipping. Some authors have recommended gentle dissection on the posterior surface of the parent vessel, if the common path was not seen. The artery can be injured during resection of the posterior part of the gyrus rectus, for exposure of this aneurysm $[2,5]$.

The recognition of the anatomical variations of Heubner's artery and the ACoA complex, and also the detailed knowledge of the microvascular relationships at that level, will allow the neurosurgeon to construct a better and safer microdissection plan, to save time and prevent postoperative neurological deficits.

\section{CONCLUSIONS}

Concluding, the origin and course of the RAH is highly variable. The RAH, in its extra- and intracerebral course, may join with the middle group of the LSA or directly with the MCA. This artery should be routinely identified during ACoA aneurysm clipping to prevent postoperative neurological deficits.

\section{ACKNOWLEDGEMENTS}

This study has been funded using Jagiellonian University Medical College statutory funds. 


\section{REFERENCES}

1. Clara M (1953) Das Nervensystem des Menschen. Georg Thieme, Leipzig, pp. 45-51.

2. Gomes F, Dujovny M, Umansky F, Ausman J, Diaz FG, Ray WJ, Mirchandani HG (1984) Microsurgical anatomy of the recurrent of Heubner. J Neurosurg, 60: 130-139.

3. Gorczyca W, Mohr G (1987) Microvascular anatomy of Heubner's recurrent artery. Neurol Res, 1987; 9: 259-264.

4. Heubner O (1872) Zur Topographie der Ernährungsgebiete der einzelnen Hirnarterien. Zentralbi Med Wiss, 10: 817-821.

5. Izci Y, Seckin H, Medow J, Turnquist C, Baskaya M (2009) Sulcal and gyral anatomy of the orbitofrontal cortex in relation to the recurrent artery of Heubner: an anatomical study. Surg Radiol Anat, 31: 439-445.

6. Kaplan HA (1965) The lateral perforating branches of anterior and middle cerebral arteries. J Neurosurg, 23: 305-310.

7. Loukas M, Louis RG Jr, Scott Childs R (2006) Anatomical examination of the recurrent artery of Heubner. Clin Anat, 19: 25-31.

8. Loukas M, Louis RG, Childs RS (2006) Anatomical examination of the recurrent artery of Heubner. Clin Anat, 19: 25-31.

9. Marinkovic S, Milisavljevic M, Kovacevic M (1986) Anatomical bases for surgical approach to the initial segment of the anterior cerebral artery. Microanatomy of Heubner's artery and perforating branches of the anterior cerebral artery. Surg Radiol Anat, 8: 7-18.

10. Mizia E, Tomaszewski KA, Lis GJ, Goncerz G, Kurzydło W (2012) The use of computer-assisted image analysis in measuring the histological structure of the human median nerve. Folia Morphol, 71: 82-85.

11. Molyneux A, Kerr R, Stratton I, Sandercock P, Clarke M, Shrimpton J, Holman R (2002) International Subarachnoid Aneurysm Trial (ISAT) of neurosurgical clipping versus endovascular coiling in 2143 patients with ruptured intracranial aneurysms: a randomized trial. J Stroke Cerebrovasc Dis, 11: 304-314.

12. Perlemuter D, Rhoton AL Jr (1975) Microsurgical anatomy of the anterior cerebral-anterior communicating-recurrent artery complex. J Neurosurg, 45: 259-272.

13. Pityński K, Skawina A, Lipczyński W, Polakiewicz J, Walocha J (1996) The posterior gastric and superior polar arteries in human fetuses. Folia Morphol, 55: 43-49.

14. Pityński K, Skawina A, Polakiewicz J, Walocha J (1998) Extraorganic vascular system of adrenal glands in human fetuses. Ann Anat, 180: 361-368.

15. Tran-Dinh $H$ (1986) The accessory middle cerebral artery: a variant of the recurrent artery of Heubner (A. centralis longa?). Acta Anat, 126: 167-171.

16. Vasović L, Ugrenović S, Jovanović I (2009) Human fetal medial striate artery or artery of Heubner. J Neurosurg Pediatr, 3: 296-301.

17. Walocha JA, Litwin JA, Bereza T, Klimek-Piotrowska W, Miodoński AJ (2012) Vascular architecture of human uterine cervix visualized by corrosion casting and scanning electron microscopy. Hum Reprod, 27: 727-732.

18. Walocha JA, Litwin JA, Miodoński AJ (2003) Vascular system of intramural leiomyomata revealed by corrosion casting and scanning electron microscopy. Hum Reprod,18: 1088-1093.

19. Walocha JA, Miodoński AJ, Nowogrodzka-Zagórska M, Kuciel R, Gorczyca J (2002) Application of a mixture of glycol polyethylenes for the preparation of microcorrosion casts: an observation. Folia Morphol, 61: 313-316.

20. Walocha JA, Szczepański W, Miodoński AJ, Gorczyca J, Skrzat J, Bereza T, Ceranowicz P, Lorkowski J, Stachura J (2003) Application of acrylic emulsion Liquitex R (Binney and Smith) for the preparation of injection specimens and immunohistochemical studies: an observation. Folia Morphol, 62: 157-161. 